\title{
Clinical characteristics and aspirin desensitization in Thai patients with a suggestive history of NSAID-exacerbated respiratory disease
}

\author{
Chamard Wongsa, ${ }^{1}$ Mongkhon Sompornrattanaphan, ${ }^{1}$ Pongsakorn Tantilipikorn, ${ }^{2}$ Torpong Thongngarm ${ }^{1}$
}

\begin{abstract}
Background: Non-steroidal anti-inflammatory drug (NSAID)-exacerbated respiratory disease (NERD) is characterized by the triad of chronic rhinosinusitis with nasal polyp, asthma, and aspirin (ASA) or NSAID hypersensitivity. Previous study of NERD has rarely been reported in Asian population.
\end{abstract}

Objectives: To investigate the clinical characteristics and outcomes of aspirin desensitization (ASAD) in Thai NERD patients.

Methods: This retrospective chart review included patients with a suggestive history of NERD with or without ASAD from the Adult Allergy Clinic of Siriraj Hospital (Bangkok, Thailand) during January 2008 to December 2018.

Results: Ten NERD patients were recruited. The median age of onset was 30 years. Comorbid atopic diseases were found in 4 patients. Asthma control level was step 3 of the Global Initiative for Asthma (GINA) guideline or greater in all patients. Five patients had reactions to more than one NSAIDs. Ibuprofen was the most common culprit agent. Reactions frequently involved the respiratory and cutaneous systems. Four patients underwent ASAD followed by ingestion of ASA 300-600 mg daily. One patient discontinued ASA after taking ASA $600 \mathrm{mg}$ daily for 3 months due to severe gastrointestinal side effect. The remaining three patients successfully continued ASA $300 \mathrm{mg}$ daily as maintenance to control sino-nasal inflammation and to prevent recurrence of nasal polyp. None of the 4 patients required sinus surgery revision.

Conclusions: NERD is a difficult-to-treat disease with unique clinical characteristics. ASAD followed by a maintenance dose of ASA $300 \mathrm{mg}$ daily was found to be effective and well-tolerated in most patients.

Key words: NSAID-exacerbated respiratory disease, aspirin desensitization, rhinosinusitis, nasal polyp, asthma, drug allergy, sinus surgery

\section{Citation:}

Wongsa, C., Sompornrattanaphan, M., Tantilipikorn, P., Thongngarm, T. (2022). Clinical characteristics and aspirin desensitization in Thai patients with a suggestive history of NSAID-exacerbated respiratory disease. Asian Pac J Allergy Immunol, 40(3), 247-253. https://doi.org/10.12932/ap-1506190583

\footnotetext{
Affiliations:

${ }^{1}$ Division of Allergy and Clinical Immunology, Department of Medicine, Faculty of Medicine Siriraj Hospital, Mahidol University, Bangkok, Thailand

2 Division of Rhinology and Allergy,

Department of Otorhinolaryngology, Faculty of Medicine Siriraj

Hospital, Mahidol University, Bangkok, Thailand
}

\author{
Corresponding author: \\ Torpong Thongngarm \\ Division of Allergy and Clinical Immunology, Department of Medicine \\ Faculty of Medicine Siriraj Hospital, Mahidol University \\ 2 Wanglang Road, Bangkoknoi, Bangkok 10700, Thailand \\ E-mail: torallergy@gmail.com
}

\section{Introduction}

Non-steroidal anti-inflammatory drug (NSAID)-exacerbated respiratory disease (NERD) is characterized by chronic inflammation of all airway passages and the presence of aspirin (ASA)/NSAID hypersensitivity. NERD patients have abnormal arachidonic acid metabolism, which leads to increased function of 5-lipoxygenase and leukotriene $\mathrm{C}_{4}$ synthase enzyme. ${ }^{1}$ This ultimately results in an increase 
in inflammatory mediators, including cysteinyl leukotriene (cys LT) and prostaglandin $\mathrm{D}_{2}\left(\mathrm{PGD}_{2}\right)$, and a decrease in anti-inflammatory cytokines like prostaglandin $\mathrm{E}_{2}\left(\mathrm{PGE}_{2}\right){ }^{2}$ Cys $\mathrm{LT}$ and $\mathrm{PGD}_{2}$ recruit inflammatory cells, including eosinophils, basophils, mast cells, T helper cell type $1\left(\mathrm{Th}_{1}\right)$, T helper cell type $2\left(\mathrm{Th}_{2}\right)$, and innate lymphoid cell type 2 $\left.\left(\mathrm{ILC}_{2}\right)\right)^{3-5}$ The inflammatory process is more prominent when cyclooxygenase (COX) enzyme blocking drugs are used, and airway inflammation persists even when patients stop taking ASA/NSAIDs. As this chronic inflammation continues over time, NERD patients develop chronic rhinosinusitis, nasal polyp formation, and asthma. ${ }^{6}$

Most NERD patients suffer from anosmia, multiple sinus infections, and severe asthma. The prevalence of NERD was $14 \%$ in patients with severe asthma compared to $7 \%$ in general population. ${ }^{7}$ Medications and surgical treatment were used to control the associated diseases, but some patients were unresponsive. In this circumstance, ASA desensitization (ASAD) is recommended as the adjunctive treatment. ${ }^{6,8}$ The precise mechanism of ASAD remains unclear; however, its efficacy has been convincingly demonstrated..$^{8-15}$

Since the 1900s, several ASAD protocols have been published. ${ }^{8,9,16}$ The common objective of these protocols is to achieve a desensitized state that allows patients to receive $325 \mathrm{mg}$ of ASA without triggering hypersensitivity reaction. The Aspirin Desensitization Joint Task Force recommends a maintenance dose of ASA 325-650 mg twice daily. ${ }^{9}$ A few studies demonstrated the efficacy of ASA at a lower dosage (100-300 mg daily). ${ }^{17-20}$ Due to the low prevalence of NERD in Asia, ${ }^{21-23}$ most clinical studies of ASAD were conducted in Caucasian populations. Thus, the objective of this study was to describe the clinical characteristics and outcomes of ASAD in Thai NERD patients.

\section{Methods}

Medical records of patients with a suggestive history of NERD at the Adult Allergy Clinic of the Faculty of Medicine Siriraj Hospital, Mahidol University during 2008-2018 were retrospectively reviewed. The suggestive history of NERD included the presence of asthma, chronic rhinosinusitis with nasal polyp (CRSNP), and ASA/NSAID hypersensitivity reaction. Clinical characteristics, demographic data, age of onset, asthma control level according to the Global Initiative for Asthma (GINA) guideline, ${ }^{24}$ forced expiratory volume in 1 second $\left(\mathrm{FEV}_{1}\right)$, number of sinus infections per year, number of asthmatic attacks per year, and the outcome of ASAD were collected. The protocol for this study was approved by the Siriraj Institutional Review Board (SIRB), Faculty of Medicine Siriraj Hospital, Mahidol University, Bangkok, Thailand (certificate of approval no. 915/2561[EC2]). The ASAD protocol used in our clinic was modified from Scripps Clinic and Joint Task Force., ${ }^{9,25}$ After the ASAD protocol was carried out, a 300-600 mg daily dose of ASA was prescribed for maintenance, as shown in Table 1.
Table 1. The aspirin desensitization protocol used in the Adult Allergy Clinic of the Faculty of Medicine Siriraj Hospital, Mahidol University

\begin{tabular}{|c|c|c|c|}
\hline Day & Time & Methods & Dose (mg) \\
\hline 1 & $9: 00 \mathrm{am}$ & ASA $(81 \mathrm{mg}) 1 / 4$ tablet & 20.25 \\
\hline 2 & $9: 00 \mathrm{pm}$ & ASA $(81 \mathrm{mg}) 1 / 2$ tablet & 40.5 \\
\hline 3 & $9: 00 \mathrm{~mm}$ & ASA $(81 \mathrm{mg}) 1$ tablet & 81 \\
\hline & ASA $(81 \mathrm{mg}) 2$ tablets & 162 \\
\hline
\end{tabular}

Abbreviation: ASA, acetylsalicylic acid

\section{Results}

Ten patients were recruited in this study. Clinical characteristics are summarized in Table 2 . The median age of onset was 30 years, with a range of $13-50$ years. The mean body mass index was $20.5 \pm 3.6 \mathrm{~kg} / \mathrm{m}^{2}$. Out of 10 patients, 5 patients reacted to 2 or more different NSAIDs, and 5 patients reacted to one. Patient \#4 had reactions to 3 NSAIDs and those reactions necessitated emergency room visits. The most common culprit agent was ibuprofen (60\%; 6/10 patients), followed by mefenamic acid (40\%; 4/10 patients), diclofenac (20\%; $2 / 10$ patients), ASA (20\%; $2 / 10$ patients), and naproxen (20\%; $2 / 10$ patients). All patients had respiratory reactions to NSAIDs. Skin reaction coexisted in 3 of them. All patients could tolerate $500 \mathrm{mg}$ of acetaminophen. No patients in this study had family history of NERD or reaction to alcohol.

Seven patients were diagnosed with difficult-to-control asthma and were treated with medication according to GINA step 4. Patient \#4 was compatible with "severe asthma" because he remained uncontrolled despite being in good compliance with prescribed medication and appropriate inhaler use. Comorbid atopic diseases were found in 4 patients. The mean percentage of predicted $\mathrm{FEV}_{1}$ was 78.8 $\pm 13.7 \%$, and the mean blood eosinophil concentration was $706.8 \pm 286$ cells $/ \mu \mathrm{L}$. Higher blood eosinophil levels were observed in atopic patients.

Almost all patients had more prominent sino-nasal symptoms than asthma symptoms. The mean number of sinus infection episodes was $2.6 \pm 3.4$ per year, while the mean number of asthma attacks was $1.4 \pm 3.7$ per year. Patient \#4 seemed to have sinus infections before aggravating asthma symptoms. Six patients had two or more sinus surgeries, while the rest had only one. Patients undergoing sinus surgery only once had a shorter follow-up period (range: 9 months-5 years) compared to those with multiple sinus surgery (range: 6-22 years). The most common pathology of nasal polyps was chronic inflammatory polyps (5/10 patients), followed by eosinophilic polyps (2/10 patients).

ASAD was performed in 4 patients, as shown in Table 3. Three of those patients had 3 sinus surgeries, except for patient \#4 who had only one sinus surgery prior to ASAD. 
Table 2. Summarization of patient demographic and clinical characteristics

\begin{tabular}{|c|c|c|c|c|c|c|c|c|c|c|}
\hline Patient number & 1 & 2 & 3 & 4 & 5 & 6 & 7 & 8 & 9 & 10 \\
\hline Gender & $\mathrm{F}$ & M & M & M & $\mathrm{F}$ & $\mathrm{F}$ & $\mathrm{F}$ & M & M & $\mathrm{F}$ \\
\hline BMI $\left(\mathrm{kg} / \mathrm{m}^{2}\right)$ & 23.4 & 26.6 & 20.7 & 24.6 & 17.7 & 20.9 & 19.7 & 28.5 & 22.4 & 17.5 \\
\hline Age at onset (years) & 22 & 36 & 30 & 30 & 28 & 46 & 18 & 13 & 46 & 50 \\
\hline Culprit drugs & ASA & Ibu & $\mathrm{Ibu}$ & $\begin{array}{l}\text { Nap, } \\
\text { Ibu, Mef }\end{array}$ & Ibu, Mef & Nap, Di & Ibu, Mef & Ibu & $\mathrm{Di}$ & $\begin{array}{l}\text { ASA, } \\
\text { Mef }\end{array}$ \\
\hline Reaction types & $\begin{array}{l}\text { Skin, } \\
\text { Resp }\end{array}$ & Resp & Resp & $\begin{array}{l}\text { Skin, } \\
\text { Resp }\end{array}$ & Resp & $\begin{array}{l}\text { Skin, } \\
\text { Resp }\end{array}$ & Resp & Resp & Resp & Resp \\
\hline Probability to positive OAC & $80 \%$ & $80 \%$ & $80 \%$ & $89 \%$ & $89 \%$ & $89 \%$ & $89 \%$ & $80 \%$ & $80 \%$ & $89 \%$ \\
\hline $\mathrm{FEV}_{1}(\%)$ & 76.9 & 75 & 75 & 80 & 96 & 87 & 72 & 81 & 48.6 & 97 \\
\hline GINA step & $4^{9}$ & $4^{9}$ & 39 & 49 & 4 & 4 & 4 & 3 & 3 & 4 \\
\hline Atopy & No & NA & Yes & No & No & Yes & NA & Yes & No & Yes \\
\hline Blood eosinophils (cells/ $\mu \mathrm{L}$ ) & 479 & 619 & 829 & 241 & 624 & 725 & NA & 1,145 & 993 & NA \\
\hline Sinus infection ${ }^{\star}$ & $2^{9}$ & 19 & $1.2^{9}$ & $12^{9}$ & 1.75 & 1.5 & 0.8 & 2.5 & 1.07 & 3.17 \\
\hline Asthma attack ${ }^{*}$ & $0.47^{9}$ & $0.08^{9}$ & 0.3 & $12^{9}$ & 0.25 & 0 & 0.2 & 1 & 0.14 & 0.17 \\
\hline Sinus surgery & 39 & 39 & 3 & $1^{s}$ & 1 & 3 & 1 & 1 & 2 & 2 \\
\hline $\begin{array}{l}\text { NP grade } \\
\text { (pathology) }\end{array}$ & $\begin{array}{c}3 \\
(\mathrm{EI})\end{array}$ & $\begin{array}{c}2 \\
(\mathrm{I})\end{array}$ & $\begin{array}{c}3 \\
(\mathrm{I})\end{array}$ & $\begin{array}{c}3 \\
(\mathrm{NA})\end{array}$ & $\begin{array}{c}2 \\
(\mathrm{I})\end{array}$ & $\begin{array}{c}3 \\
(\mathrm{I})\end{array}$ & $\begin{array}{c}3 \\
(\mathrm{NA})\end{array}$ & $\begin{array}{c}3 \\
(\mathrm{E})\end{array}$ & $\begin{array}{c}3 \\
(\mathrm{I})\end{array}$ & $\begin{array}{c}3 \\
(\mathrm{NA})\end{array}$ \\
\hline Total follow-up (years) & 22 & 16 & 11 & 1.25 & 4 & 16 & 5 & 4 & 14 & 6 \\
\hline Recurrence of NP & Yes & Yes & Yes & No & No & Yes & No & No & No & Yes \\
\hline
\end{tabular}

${ }^{*}$ Numbers per year, 'Before aspirin desensitization

Abbreviations: ASA, acetylsalicylic acid; BMI, body mass index; Di, diclofenac; EI, eosinophilic inflammation; F, female; FEV ${ }_{1}$, forced expiratory volume in 1 second; GINA, The Global Initiative for Asthma; Ibu, ibuprofen; M, male; Mef, mefenamic acid; NA, unavailable data; Nap, naproxen; NP, nasal polyp; OAC, oral aspirin challenge; I, chronic inflammatory nasal polyp; Resp, respiratory symptoms

Table 3. Clinical characteristics and outcomes of 4 patients who underwent aspirin desensitization

\begin{tabular}{|c|c|c|c|c|}
\hline Patient number & 1 & 2 & 3 & 4 \\
\hline Medication during ASAD & AH, LTRA & AH, LTRA & AH, LTRA & AH, LTRA, CS \\
\hline $\begin{array}{l}\text { Interval between surgery and ASAD } \\
\text { (weeks) }\end{array}$ & 4 & 4 & 8 & 9 \\
\hline $\begin{array}{l}\text { Reaction during ASAD } \\
\text { (reaction dose) }\end{array}$ & $\begin{array}{l}\text { Mild chest tightness } \\
\qquad(40 \mathrm{mg})\end{array}$ & $\begin{array}{l}\text { Itchy eye, nasal congestion } \\
\qquad(160 \mathrm{mg})\end{array}$ & $\begin{array}{l}\text { Erythema, mild chest } \\
\text { tightness }(202.5 \mathrm{mg})\end{array}$ & $\begin{array}{l}\text { Mild chest tightness } \\
\text { (40 mg) }\end{array}$ \\
\hline ASA dosage after ASAD & $\begin{array}{l}600 \mathrm{mg} / \text { day } \\
\text { for } 2 \text { years }\end{array}$ & $\begin{array}{l}600 \mathrm{mg} / \text { day } \\
\text { for } 3 \text { months }\end{array}$ & $300 \mathrm{mg} /$ day & $300 \mathrm{mg} /$ day \\
\hline Current ASA dosage & $300 \mathrm{mg} /$ day & - & $300 \mathrm{mg} /$ day & $300 \mathrm{mg} /$ day \\
\hline Follow-up after ASAD (year) & 5 & 2 & 1 & 9 months \\
\hline \multicolumn{5}{|l|}{ Sinus infection ${ }^{\star}$} \\
\hline Before ASAD & 2 & 1 & 1.20 & 12 \\
\hline After ASAD & 1.2 & 0.25 & 0 & 1.33 \\
\hline \multicolumn{5}{|l|}{ Asthma attack ${ }^{*}$} \\
\hline Before ASAD & 0.47 & 0.08 & 0.30 & 12 \\
\hline After ASAD & 1.2 & 0 & 0 & 1.33 \\
\hline
\end{tabular}


Table 3. (Continued)

\begin{tabular}{|l|c|c|c|}
\multicolumn{1}{|c|}{ Patient number } & $\mathbf{1}$ & $\mathbf{2}$ & $\mathbf{3}$ \\
\hline GINA step at last follow-up & 4 & 3 & 3 \\
Side effect of ASA & No & Yes (GI) & Yes (GI) \\
PPI prophylaxis & Yes & Yes & Yes \\
Recurrent of NP after ASAD & No & No & Grade I \\
\hline
\end{tabular}

${ }^{*}$ Numbers per year

Abbreviations: ASA, acetylsalicylic acid; ASAD, aspirin desensitization; AH, antihistamine; CS, corticosteroid; LTRA, leukotriene receptors antagonist; GI, gastrointestinal; GINA, Global Initiative for Asthma; NP, nasal polyp; PPI, proton pump inhibitor
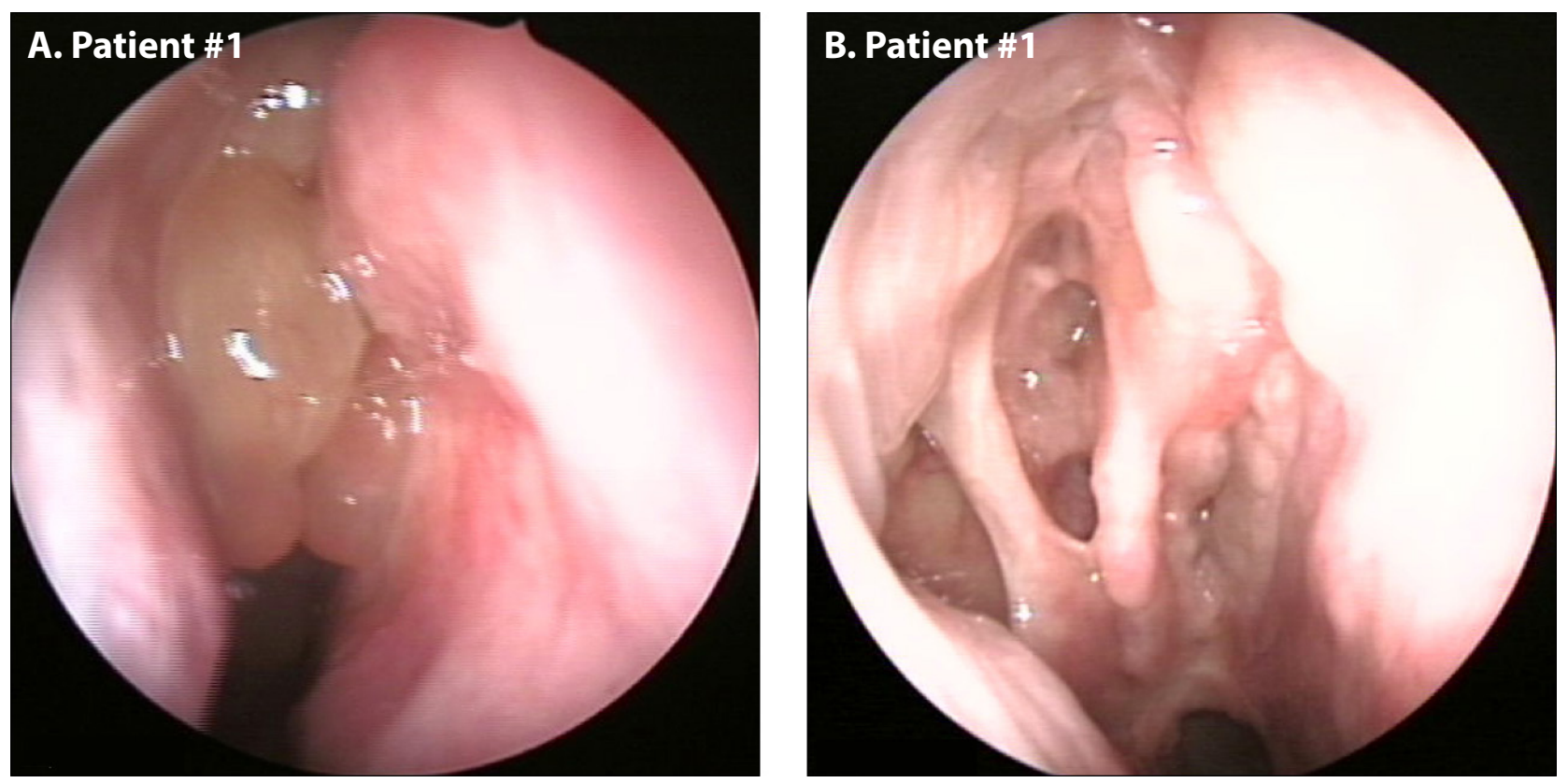

Figure 1. Nasal endoscopic finding in patient \#1. A) Preoperative finding showed right nasal polyps grade III. B) Five years after aspirin desensitization followed by $300 \mathrm{mg}$ of aspirin daily showed no recurrence of nasal polyps.
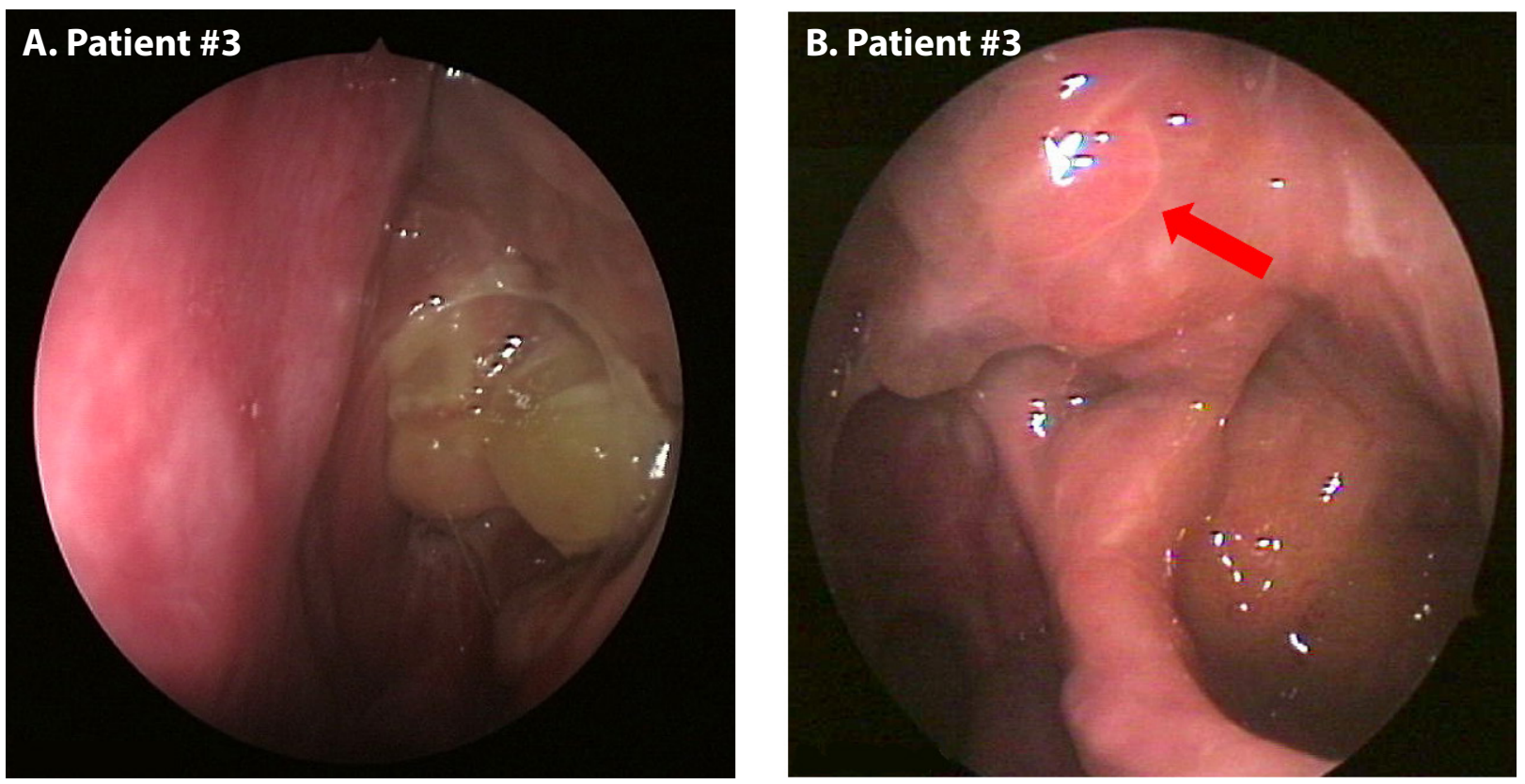

Figure 2. Nasal endoscopic finding in patient \#3. A) Preoperative finding showed left nasal polyps grade III. B) Two years after aspirin desensitization followed by $300 \mathrm{mg}$ of aspirin daily showed nasal polyps grade I (arrow). 
The mean interval between sinus surgery and ASAD was 6.25 weeks. All patients continued their current medications during ASAD, including antihistamine and leukotriene antagonists. We prescribed intravenous dexamethasone as a premedication before ASAD in patient \#4 due to his poorly controlled asthma status. All patients were successfully desensitized within 3 days without serious adverse events. During ASAD, only mild respiratory and skin reactions occurred, both of which were easily relieved by symptomatic treatment. The mean elicitation dose of ASA was $110 \mathrm{mg}$. Two patients continued $600 \mathrm{mg}$ daily of ASA, whereas the other two took $300 \mathrm{mg}$ daily. All patients took $20 \mathrm{mg}$ daily of omeprazole for prevention of gastrointestinal (GI) side effect. Patient \#1 who started with $600 \mathrm{mg}$ daily of ASA for 2 consecutive years and then decreased to $300 \mathrm{mg}$ daily for 3 years. Her asthma was well-controlled and no nasal polyps recurred during the follow-up period. Patient \#2 who started with $600 \mathrm{mg}$ daily of ASA for 3 months discontinued ASA due to the development of GI side effect. Thereafter, a maintenance dose of $300 \mathrm{mg}$ daily of ASA was prescribed as a maintenance dose in patient \#3 and patient \#4. No GI side effects were reported.

The mean number of sinus infections and asthmatic attacks per year before and after ASAD was decreased from $4.05 \pm 5.32$ to $0.36 \pm 0.57$, and $3.21 \pm 5.86$ to $1.80 \pm$ 2.86, respectively. Asthma control level in the ASAD group remained unchanged compared to baseline, except for patient \#2 who had treatment de-escalation from GINA step 4 to step 3 .

The longest follow-up period after ASAD was 5 year in patient \#1. She had no recurrence of nasal polyps, as shown in Figure 1. Patient \#3 developed regrowth of nasal polyps grade I, but no surgical revision was required (Figure 2). In contrast, two patients (patient \#6 and patient \#10) who did not undergo ASAD developed frequent regrowth of nasal polyps grade III despite multiple sinus surgeries.

\section{Discussion}

We described the clinical characteristics of ten patients with a suggestive history of NERD who were treated at our Adult Allergy Clinic during 2008-2018, and we reported the clinical outcomes of four out of ten patients who underwent ASAD. The number of patients in our cohort was limited due to recruitment from a single-center and the known low prevalence of NERD in Asia. The prevalence of NERD in patients with CRSNP in a study from China was $0.57 \% .{ }^{21}$ The prevalence of NERD among Korean asthma patients was $5.8 \%{ }^{22}$ A recent meta-analysis, which consisted of 27 studies involving worldwide population, found the prevalence of NERD was $7.15 \%$ among asthmatics, $14.89 \%$ among severe asthmatics, 9.69\% among patients with NP and 8.7\% among patients with CRS. ${ }^{7}$ This suggests that the prevalence of NERD in Asia is relatively low when compared with the data from Europe and America.

The most common culprit agent in our study was ibuprofen $(60 \%)$, followed by mefenamic acid (40\%), naproxen (20\%), diclofenac (20\%), and ASA (20\%). Common culprit NSAIDs may vary according to the region because they are available over-the-counter in some regions and not in others.
The common culprit NSAIDs in European cohort were ASA $(82 \%)$ and pyrazolones (9\%), ${ }^{26}$ whereas those in American cohort were ASA (80\%) and ibuprofen (41\%). ${ }^{27}$ Alcohol intolerance was the unique characteristic in NERD patients. Seventy-seven percent of NERD patients developed nasal or lower respiratory airway symptoms when drinking alcohol in a few sips. ${ }^{28}$ Interestingly, most of them could tolerate alcohol after successful ASAD. ${ }^{28}$ However, the majority of our patients could tolerate alcohol consumption according to their clinical history. To the best of our knowledge, no NERD patient with alcohol intolerance was reported in Asian population.

Atopy is a recognized common comorbidity in NERD patients. ${ }^{29}$ Four patients in this study had aeroallergen sensitization, as demonstrated by skin prick test or ImmunoCAP. A high prevalence of allergic sensitization was also observed in American and Korean studies that reported atopic prevalence in as many as $50-60 \%$ of NERD patients. ${ }^{22,27}$ The hallmark of NERD pathology is chronic eosinophilic inflammation due to an increase in cys LT and $\mathrm{PGD}_{2}$, and a decrease in PGE Eosinophilia was commonly found in NERD patients. ${ }^{22,26,27}$ Our patients also had eosinophilia, defined as an absolute eosinophil count more than 500 cells $/ \mu \mathrm{L}$, except for patient $\# 1$ and \#4 who recently received systemic corticosteroids that may have effectuated a reduction in eosinophil level.

NERD patients also had a significant reduction in lung function as determined by pulmonary function test. ${ }^{29}$ Seven patients in our study had difficult-to-control asthma with obstructive pattern demonstrated by mean predicted $\mathrm{FEV}$ of $78.8 \pm 13.7 \%$. The mean predicted $\mathrm{FEV}_{1}$ in Korean and American NERD patients was $82.9 \pm 21.8 \%$ and $80.0 \pm 18.0 \%$ respectively. ${ }^{22,27}$ Therefore, a significant reduction in lung function is quite consistent among studies.

Previous study demonstrated that a history of having 1 or 2 episodes of respiratory reactions to ASA/NSAIDs had a probability of achieving positive oral ASA challenge (OAC) of $80 \%$ and $89 \%$, respectively. ${ }^{30}$ All patients in our cohort reported an episode of respiratory reaction to at least 1 NSAID. Although we did not perform OAC to confirm the diagnosis, they still had a probability of positive OAC of as high as $80-89 \%$ and performing OAC in every case might carry an unavoidable risk, especially in brittle asthmatics. Moreover, four patients who underwent ASAD developed respiratory symptoms during the procedure, which adequately supported the hypersensitivity reaction.

Interestingly, patient \#1, 4, 6 had both of cutaneous and respiratory reactions which does not fit in any classification of NSAIDs hypersensitivity according to widely accepted ENDA classification. ${ }^{31}$ Blended type might use to describe this reaction. ${ }^{31}$ Some author named it a cross-reactive anaphylaxis-like reaction. ${ }^{32}$ Although definition and clinical characteristic in blended type was controversial, they had similar underlying mechanism that was non-immunological hypersensitivity reaction via COX-1 inhibition among NERD, NSAID-induced urticaria and angioedema (NIUA), NSAID-exacerbated cutaneous disease (NECD) and blended type. ${ }^{33}$ Dona, et al. reported that blended type was the second most common reaction found in non-immunological hypersensitivity as $28 \% .{ }^{34}$ Blended type was similar to NERD in many aspects such as presence of underlying rhinitis, asthma, 
and had a $77 \%$ positive nasal provocation test by lysine acetylsalicylate (NPT-LASA), compared with $78 \%$ in NERD. ${ }^{34}$ Alternatively, nasal polyp was more commonly found in NERD than blended type. ${ }^{34}$ Either blended type or NERD was identified in patient\#4 and \#6, they still had a high probability to positive OAC $(89 \%),{ }^{30}$ or NPT-LASA $(77 \%){ }^{34}$ Immunological hypersensitivity reaction via IgE-mediated is another mechanism of NSAID hypersensitivity that classifying as single-NSAID induce urticaria, angioedema, and anaphylaxis. ${ }^{31}$ Since we did not perform drug provocation test with other dissimilar NSAIDs, we could not declare the exact mechanism in patient\#1. However, patient\#1 had asthma, CRSNP, and reacted to 1 NSAID which predict the probability of NERD as high as $80 \% .^{30}$

Berges-Gimeno, et al. studied 172 NERD patients treated with ASAD and ASA daily, and they found that $87 \%$ of patients who completed 1 year or more of ASA treatment experienced improvement in sinus infections, sense of smell, asthma symptoms, and decreased prednisone use..$^{10}$ Moreover, none of those patients required further sinus revision surgery during the 5-year study period. ASAD should be performed within four weeks after sinus surgery, particularly for preventing the recurrence of nasal polyps. ${ }^{14}$ Four patients in our cohort underwent ASAD without serious adverse event and were able to successfully continue $300-600 \mathrm{mg}$ daily of ASA. Efficacy of ASAD was observed in our patients. Patients \#1-3 demonstrated improvement in sino-nasal symptoms, while patient \#4 required a longer follow-up. At the time this report was written, no patients had thus far required sinus revision surgery. Variation in asthmatic outcome was observed in our cohort. Patients \#2 and \#3 had improvement in asthma symptoms, whereas patient \#1 became worsening. This observed deterioration may be due to various triggers, especially in brittle asthmatic individuals, such as particulate matter, chemical irritants, aeroallergens, infections, and stress. $^{24,35}$ There is still a lack of well-controlled trials to demonstrate the efficacy of ASAD on asthma outcome. Some studies showed improvement in asthma outcomes, whereas others reported no significant changes after ASAD. ${ }^{13,15,16}$

According to the ASAD Joint Task Force, the maintenance dose of ASA after ASAD should be 650-1,300 mg daily. ${ }^{9}$ However, only $81 \mathrm{mg}$ and $300 \mathrm{mg}$ of ASA tablet formulation are available in Thailand. Although our protocol initially used $600 \mathrm{mg}$ daily of ASA as a maintenance dose, patient \#2 developed severe gastric pain leading to discontinuation of ASA after 3 months. However, patient \#1 was able to tolerate $600 \mathrm{mg}$ for 2 years, and then $300 \mathrm{mg}$ daily of ASA afterwards, which resulted in well-controlled sino-nasal symptoms and no nasal polyp recurrence. We subsequently used $300 \mathrm{mg}$ daily of ASA as a standard dose in the Adult Allergy Clinic at our center. Patients \#3 and \#4 received 300 mg daily of ASA with favorable outcome. Previous study reported that a higher dose of ASA was better than a lower dose, with a response rate of $69 \%$ for the daily dose of 2,600 $\mathrm{mg}, 60 \%$ for $1,300 \mathrm{mg}$, and $57 \%$ for $325 \mathrm{mg} .{ }^{16}$ However, $14 \%$ of patients discontinued ASA treatment mainly due to gastric pain and bleeding. ${ }^{10}$ To reduce GI side effects, there was an attempt to determine the lowest effective maintenance dose of ASA. Fruth K, et al. reported that $100 \mathrm{mg}$ daily of ASA was effective for preventing relapse of nasal polyp. ${ }^{19}$ However, there was a $50 \%$ drop-out rate in that study. Gosepath J, et al. also reported the effectiveness of low-dose ASA, but they recruited a study population that had mild severity. ${ }^{17}$ Rozsasi A, et al. found that $300 \mathrm{mg}$ daily of ASA was superior to 100 mg for reducing both nasal and asthma symptoms. ${ }^{18}$ After one-year of follow-up, all patients who received $100 \mathrm{mg}$ daily of ASA had recurrent nasal polyps and required revision sinus surgery. ${ }^{18}$ Comert S, et al. recommended $300 \mathrm{mg}$ daily of ASA to be an effective dose for ASA treatment during 1-3 years of follow-up. ${ }^{20}$ This regimen reduced the need for sinus revision surgery with an incidence of GI side effects of 5.1\%-10\%. ${ }^{18,20}$ Therefore, $300 \mathrm{mg}$ daily of ASA appears to be sufficient for controlling sinus inflammation and preventing the relapse of nasal polyps.

The limitations of this study include its small sample size and the fact that we did not perform OAC to confirm the diagnosis of NERD in all cases. Our modified ASAD protocol has not been validated. Hence, its efficacy and safety should be considered for further investigation. The measurement of clinical outcome and hypersensitivity reaction in our study was mainly subjective. We did not perform objective measurements, such as nasal inspiratory flow, acoustic rhinomanometry, or changes of $\mathrm{FEV}_{1}$ at baseline during ASAD which should be done in the future study. The retrospective design of our study also increased the possibility of undeclared confounding factors and biases.

\section{Conclusion}

NERD patients in this study were in their third decade of life, almost equal between genders, and there was no alcohol intolerance. Forty percent of patients had atopic disease as a comorbidity. Our patients had uncontrolled sinus infection and difficult-to-treat asthma, and most required multiple sinus surgeries. ASAD was a safety procedure. Continuation of $300 \mathrm{mg}$ daily of ASA should be considered as a specific treatment for NERD to reduce sino-nasal inflammation and delay sinus revision surgery.

\section{Acknowledgements \\ None}

\section{Conflict of interest declaration}

All authors declare no personal or professional conflicts of interest, and no financial support from the companies that produce and/or distribute the drugs, devices, or materials described in this report.

\section{Funding disclosure}

This was an unfunded study.

\section{References}

1. Steinke JW, Bradley D, Arango P, Crouse CD, Frierson H, Kountakis $\mathrm{SE}$, et al. Cysteinyl leukotriene expression in chronic hyperplastic sinusitis-nasal polyposis: Importance to eosinophilia and asthma. J Allergy Clin Immunol. 2003;111(2):342-9. 
2. Buchheit KM, Cahill KN, Katz HR, Murphy KC, Feng C, Lee-Sarwar $\mathrm{K}$, et al. Thymic stromal lymphopoietin controls prostaglandin D2 generation in patients with aspirin-exacerbated respiratory disease. J Allergy Clin Immunol. 2016;137(5):1566-76.e5.

3. Moretta L, Locatelli F. Innate lymphoid cells in normal and disease: An introductory overview. Immunol Lett. 2016;179:1.

4. Steinke JW, Liu L, Huyett P, Negri J, Payne SC, Borish L. Prominent role of IFN-gamma in patients with aspirin-exacerbated respiratory disease. J Allergy Clin Immunol. 2013;132(4):856-65.e1-3.

5. Chang JE, Doherty TA, Baum R, Broide D. Prostaglandin D2 regulates human type 2 innate lymphoid cell chemotaxis. J Allergy Clin Immunol. 2014;133(3):899-901.e3

6. White AA, Stevenson DD. Aspirin-Exacerbated Respiratory Disease. N Engl J Med. 2018;379(11):1060-70.

7. Rajan JP, Wineinger NE, Stevenson DD, White AA. Prevalence of aspirin-exacerbated respiratory disease among asthmatic patients: A meta-analysis of the literature. J Allergy Clin Immunol. 2015;135(3): 676-81.e1.

8. Kowalski ML, Agache I, Bavbek S, Bakirtas A, Blanca M, Bochenek G, et al. Diagnosis and management of NSAID-Exacerbated Respiratory Disease (N-ERD)-a EAACI position paper. Allergy. 2018;00:1-12.

9. Macy E, Bernstein JA, Castells MC, Gawchik SM, Lee TH, Settipane RA, et al. Aspirin challenge and desensitization for aspirin exacerbated respiratory disease: a practice paper. Ann Allergy Asthma Immunol. 2007; 98:172-4.

10. Berges-Gimeno MP, Simon RA, Stevenson DD. Long-term treatment with aspirin desensitization in asthmatic patients with aspirin-exacerbated respiratory disease. J Allergy Clin Immunol. 2003;111(1):180-6.

11. Sweet JM, Stevenson DD, Simon RA, Mathison DA. Long term effects of aspirin (ASA) desensitization-treatment for ASA sensitive rhinosinusitis-asthma. J Allergy Clin Immunol. 1990;85:59-65.

12. Stevenson DD, Hankammer MA, Mathison DA, Christiansen SC, Simon RA. Aspirin desensitization treatment of aspirin-sensitive patients with rhinosinusitis-asthma: Long-term outcomes. J Allergy Clin Immunol. 1996;98:751-8.

13. Xu JJ, Sowerby L, Rotenberg BW. Aspirin desensitization for aspirin-exacerbated respiratory disease (Samter's Triad): a systematic review of the literature. Allergy Rhinol. 2013;3:915-20.

14. Cho KS, Soudry E, Psaltis AJ, Nadeau KC, Mcghee SA, Nayak JV, et al. Long-term Sinonasal Outcomes of Aspirin Desensitization in Aspirin Exacerbated Respiratory Disease. Otolaryngology-Head and Neck Surgery 2014;151(4):575-81.

15. Swierczynska-Krepa M, Sanak M, Bochenek G, Strek P, Cmiel A, Gielicz A, et al. Aspirin desensitization in patients with aspirin-induced and aspirin-tolerant asthma: a double-blind study. J Allergy Clin Immunol. 2014;134(4):883-90.

16. Stevenson DD, Pleskow WW, Simon RA, Mathison DA, Lumry WR, Schatz M, et al. Aspirin-sensitive rhinosinusitis asthma: A double-blind crossover study of treatment with aspirin. J Allergy Clin Immunol. 1984;73:500-7.

17. Gosepath J, Schaefer D, Amedee RG, Mann WJ. Individual Monitoring of Aspirin Desensitization. Arch Otolaryngol Head Neck Surg. 2001; 127:316-21.

18. Rozsasi A, Polzehl D, Deutschle T, Smith E, Wiesmiller K, Riechelmann $\mathrm{H}$, et al. Long-term treatment with aspirin desensitization: a prospective clinical trial comparing 100 and $300 \mathrm{mg}$ aspirin daily. Allergy. 2008;63:1228-34
19. Fruth K, Pogorzelski B, Schmidtmann I, Springer J, Fennan N, Fraessdorf N, et al. Low-dose aspirin desensitization in individuals with aspirin-exacerbated respiratory disease. Allergy. 2013;68(5):659-65.

20. Comert S, Celebioglu E, Yucel T, Erdogan T, Karakaya G, Onerci M, et al. Aspirin $300 \mathrm{mg} /$ day is effective for treating aspirin-exacerbated respiratory disease. Allergy. 2013;68:1443-51.

21. Fan Y, Feng S, Xia W, Qu L, Li X, Chen S, et al. Aspirin-exacerbated respiratory disease in China: a cohort investigation and literature review. Am J Rhinol Allergy. 2012;26(1):e20-2.

22. Moon JY, Kim SH, Kim TB, Kim SH, Chang YS, Lee JH, et al Aspirin-intolerant asthma in the Korean population: prevalence and characteristics based on a questionnaire survey. Respir Med. 2013;107(2): 202-8.

23. Yoshimine F, Hasegawa T, Suzuki E, Terada M, Koya T, Kondoh A, et al. Contribution of aspirin-intolerant asthma to near fatal asthma based on a questionnaire survey in Niigata Prefecture, Japan. Respirology. 2005; $10: 477-84$

24. Ginasthma.org[Internet]. Fontana: Global Initiative for Asthma. Global Strategy for Asthma Management and Prevention; c2019 [cited 2019 May 23]. Available from: https://www.ginasthma.org

25. White AA, Stevenson DD. Aspirin desensitization in aspirin-exacerbated respiratory disease. Immunol Allergy Clin North Am. 2013;33(2):211-22.

26. Szczeklik A, Ankowska EN, Duplaga M. Natural history of aspirin-induced asthma. Eur Respir J. 2000;16:432-6.

27. Berges-Gimeno MP, Simon RA, Stevenson DD. The natural history and clinical characteristics of aspirin-exacerbated respiratory disease. Ann Allergy Asthma Immunol. 2002;89:474-8.

28. Glicksman JT, Parasher AK, Doghramji L, Brauer D, Waldram J, Walterset K, et al. Alcohol-induced respiratory symptoms improve after aspirin desensitization in patients with aspirin-exacerbated respiratory disease. Int Forum Allergy Rhinol. 2018;8:1093-7.

29. Stevens WW, Peters AT, Hirsch AG, Nordberg CM, Schwartz BS, Mercer D, et al. Clinical Characteristics of Patients with Chronic Rhinosinusitis with Nasal Polyps, Asthma, and Aspirin-Exacerbated Respiratory Disease. J Allergy Clin Immunol Pract. 2017;5(4):1061-70.e3.

30. Dursun AB, Woessner KA, Simon RA, Karasoy D, Stevenson DD Predicting outcomes of oral aspirin challenges in patients with asthma, nasal polyps, and chronic sinusitis. Ann Allergy Asthma Immunol. 2008;100:420-5.

31. Kowalski ML, Asero R, Bavbek S, Blanca M, Blanca-Lopez N, Bochenek $\mathrm{G}$, et al. Classification and practical approach to the diagnosis and management of hypersensitivity to nonsteroidal anti-inflammatory drugs. Allergy. 2013;68:1219-32.

32. Quiralte J, Blanco C, Delgado J, Ortega N, AlcáNtara M, Castillo R, et al. Challenge-Based Clinical Patterns of 223 Spanish Patients With Nonsteroidal Anti-Inflammatory-Drug-Induced-Reactions. J Investig Allergol Clin Immunol. 2007;17(3):182-8

33. Walters KM, Woessner KM. An Overview of Nonsteroidal Antiinflammatory Drug Reactions. Immunol Allergy Clin North Am. 2016;36(4):625-41.

34. Dona I, Barrionuevo E, Salas M, Laguna JJ, Agundez J, Garcia-Martin E, et al. NSAIDs-hypersensitivity often induces a blended reaction pattern involving multiple organs. Sci Rep. 2018;8(1):16710.

35. Sompornrattanaphan M, Thongngarm T, Tantilipikorn P, Kreetapirom P, Foo J. The Contribution of Outdoor Fine Particulate Matter to Indoor Air Quality in Bangkok Metropolitan Region, Thailand - Are Indoor Dwellers Safe? Siriraj Med J. 2018;70(4):7. 